\title{
Semi-Friction Stir Processing the method for improvement of the product surface layer
}

\author{
Piotr Uliasz ${ }^{1, a}$, Tadeusz Knych ${ }^{1, b}$, Marek Blicharski $^{2, c}$, Marzena Piwowarska $^{1, d}$ \\ ${ }^{1}$ Department of Non-ferrous Metals, AGH University of Science and Technology, Av. Mickiewicza \\ 30, 30-059 Kraków, Poland \\ ${ }^{2}$ Departament of Metals Engineering and Industrial Computer Science, AGH University of Science \\ and Technology, Av. Mickiewicza 30, 30-059 Kraków, Poland
}

apuliasz@agh.edu.pl, btknych@agh.edu.pl, 'mablich@agh.edu.pl, ${ }^{d}$ marzenap@agh.edu.pl

Keywords: Friction Stir Processing, surface processing, aluminium cast repair, EN AC-42100.

\begin{abstract}
The paper deals with the application of semi-Friction Stir Processing (s-FSP) to the improvement of surface contact within the flange joints used in casings of high-voltage switchgears which are filled with electroinsulating SF6 gas. The goal of the research was to design the appropriate tool (shape and size) as well as to select parameters for this s-FSP process which results in the removal of casting defects from the surface layer of the final product. The characteristics of the proposed process is the redesign of a tool shape, which is not equipped with an element penetrating and stirring the material (pin). Moreover, the process does not require the usage of sophisticated devices or tilting the tool relative to the treated surface during the process. The elaborated process is useful for repairing the defective castings, and in the case of high-voltage switchgears, it allows to achieve the required tightness of the joints.
\end{abstract}

\section{Introduction}

The practical problem solved within the presented research concerns the improvement of facing surface contact within the flange joint of the $\mathrm{SF}_{6}$ gas filled power switchgear (Gas Insulated Switchgear - GIS). During the operation of the switchgear it is necessary to maintain a constant working pressure of $\mathrm{SF}_{6}$. If the pressure were to reduce by $0.05 \mathrm{MPa}$, an emergency disconnection of the switchgear occurs. The supporting frames are made of $\mathrm{Al}$ alloys produced by casting technology (EN AC-42100). After casting, final machining and assembly, the frames are tested for seal and tightness. As a result of machining some casting defects, previously not visible, are revealed and this is a reason why some of the frames do not meet the test requirement according to the EN 50052, resulting a potentially substantial economic losses. These defects constitute the main reason for the $\mathrm{SF}_{6}$ gas leakage in the GIS frames. Due to structural constraints, the acceptable tolerance range on the frame's height is $\pm 0.3 \mathrm{~mm}$. Therefore, during the processing of the flange's sealing face, not more than $0.3 \mathrm{~mm}$ of the material's thickness can be removed. For this reason, a study was undertaken in order to develop a repair technology of the faulty frames of the switchgears.

The study and evolution of Friction Stir Welding (FSW) [1] contributed to the development of other novel processes using the idea of the friction welding with stirring the welded material. One such process is Friction Surfacing [2]. Another method derived from the FSW is Friction Stir Processing (FSP) [1, 3]. FSP uses the same methodology as FSW, but FSP is used to modify the local microstructure and does not join metals together. Like FSW, the FSP technology involves plunging a rapidly rotating, non-consumable tool, comprised of a profiled pin and larger diameter shoulder, into the surface and then traversing the tool across the surface. Frictional heating and extreme deformation occurs causing plasticised material (constrained by the shoulder) to flow around the tool and forms (upon cooling) a defect-free recrystallized, fine grain microstructure. FSP zones can be produced to depths of several millimeters, with a gradual transition from a finegrained, thermomechanically worked microstructure to the underlying original microstructure. The main applications of the process include: elimination of casting defects in the form of porosities or 
shrinkages and refinement of surface microstructures, thereby improving strength and ductility and increasing resistance to corrosion and fatigue $[1,4,5]$. The application of this method is used in the processes of bending and stamping [1,6]. FSP can also produce fine-grained microstructures through the thickness to impart superplasticity as well as produce in-situ surface composite by stirring the base material with the strengthening particles, e.g. SiC [1, 3].

The concept of FSP served as the basis for the development of a new technology that eliminates casting defects on the castings' surface [7]. The modification of FSP lies in the implementation of a modified tool that only slightly penetrates the worked material, but exerts a large compressive force inducing plastic deformation in the surface layers. The method combines the traditional FSP with ball burnishing of the metal surface. The tool shape must be capable for cold working of the processed material and maintaining its required dimensional tolerance.

The goal of the presented research was to design the appropriate tool (shape and size) as well as to select parameters for this semi-FSP process that would result in the removal of casting defects from the surface layer of the final product. This method was applied to improve the flange joint contacts used in the casings of high-voltage, switchgears which are filled with electroinsulating $\mathrm{SF}_{6}$ gas. The research was realized in two stages: laboratory (preliminary) and industrial.

\section{Research and discussion}

Preliminary. The laboratory studies were comprised of trials in which the semi-FSP was applied to material samples with controlled defects introduced. The experiments were carried out on a milling machine. For that purpose, the test sample was mounted on the miller table in such a way that the surface to be processed was perpendicular to the axis of the working tool. Subsequently, several holes, simulating the surface defects, were drilled on the sample surface (diameter of $1.5 \mathrm{~mm}$ and depth of $3 \mathrm{~mm}$ ). After that the process began and the deformation was applied to the sample surface. The tool has a shape of a truncated cone. Its tip was in the form of a flat surface of $4 \mathrm{~mm}$ in diameter. The tool was pressed into the sample to the depth of about $0.3 \mathrm{~mm}$. The process was realized at a rotational speed of the head of 960 rotations per minute (rpm) and a traversing speed of $180 \mathrm{~mm} / \mathrm{min}$. The temperature measured behind the tool on the sample surface was approximately $150{ }^{\circ} \mathrm{C}$.

When the process was completed, the specimens for microscopic examination were excised from the processed surface layer parallel to the axes of the drilled holes and perpendicular to the treated surface. The metallographic investigation revealed differences in microstructure between the area affected by the tool and the base material. The drilled holes were covered by the newly produced layer with a refined microstructure which contrasted with the casting structure below (Fig. 1).

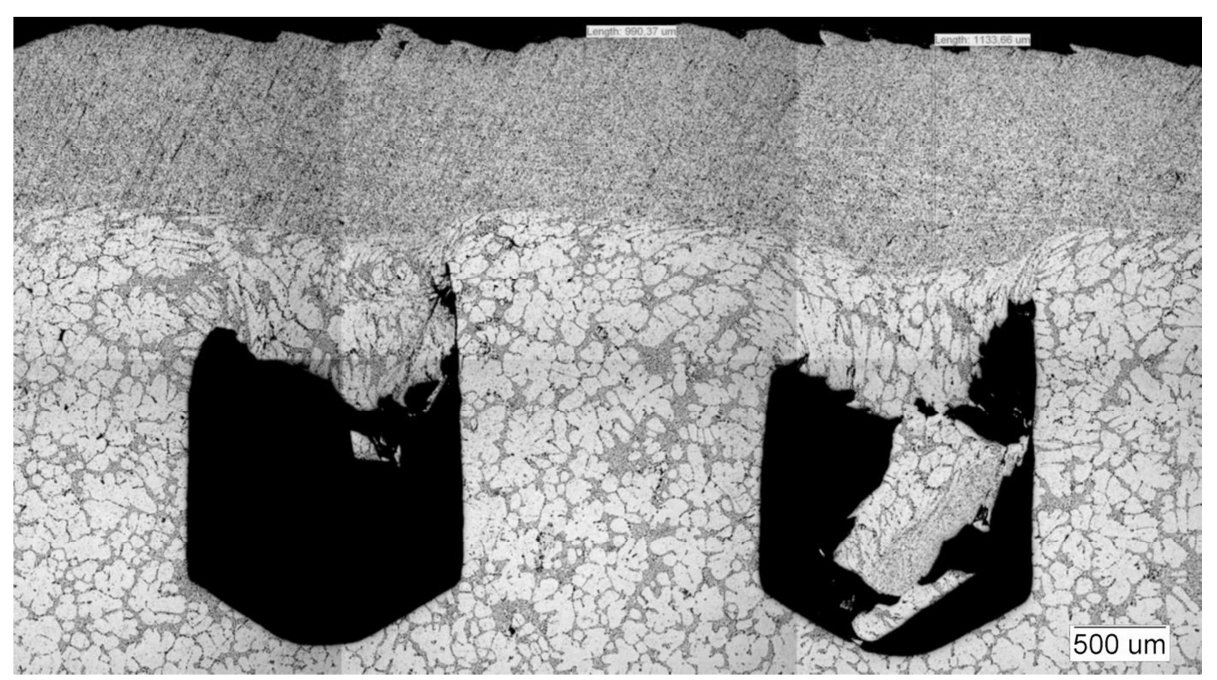

Fig. 1. Microstructure of the specimen after treatment general view of the holes 
By analogy to FSP, the zone with the refined microstructure is referred to as the stir zone (SZ). The zone constitutes a compact layer, about $1.1 \mathrm{~mm}$ thick, without defects. Below the SZ there is a thermo-mechanically affected zone (TMAZ). TMAZ is a transition area between the SZ and the unaffected casting structure of the base material $(\mathrm{BM})$. In the processed layer no casting defects in the form of pores or other discontinuities were detected. Inside the remaining holes some protrusions of material with almost unchanged cast microstructure were observed. The deformation and stirring of the near-surface material during the process was so intense that the microstructure of the layer just above the holes did not differ from the microstructure of the material above the solid base. This provides evidence that the process is able to seal the holes with tight and defect-free material.

Industrial. The industrial research of the application of the semi-FSP process was performed on castings that did not meet the tightness requirements. The first two flanges were processed at a rotational speed of $2000 \mathrm{rpm}$ and a fed rate of $150 \mathrm{~mm} / \mathrm{min}$. The interval between particular cycles of the tool's operation was $4 \mathrm{~mm}$. The applied process parameters were sufficient to increase the temperature of the processed flange to above $200^{\circ} \mathrm{C}$. The treatment proceeded for more than 40 minutes. In order to shorten this period of time, the process parameters were gradually changed. The acceleration of the process by increasing the tool feed rate and by increasing the intervals between the consecutive deformation cycles reduced the temperature of the casting surface.

The specimens used for microscopic examination and hardness tests were excised from the surface layer of the flanges. The processed surface layer of the casting consists of the stir zone (Fig. 2 a) which transitioned first into the TMAZ zone (Fig. 2 b) and finally into the microstructure of the base material (Fig. 2 c). The stir zone (SZ) is characterized by a uniform and compact microstructure, free from defects in the form of porosities or shrinkages.
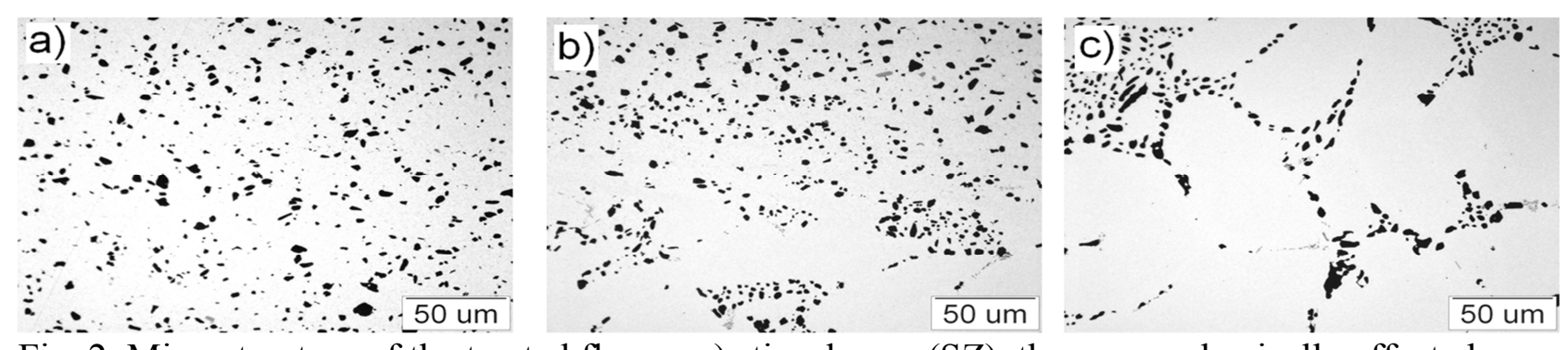

Fig. 2. Microstructure of the treated flange: a) stirred zone (SZ), thermo mechanically effected zone

(TMAZ), c) base material (BM)

The hardness of the material in the stir zone was approximately $60 \mathrm{HV}$ while in the base material zone (BM) it was about $80 \mathrm{HV}$. Between the two zones, the transition zone (TMAZ) exhibits hardness which increased with the distance from the surface toward the base material. The range of the occurrence of the zone with decreased hardness was about $1 \mathrm{~mm}$, and the transition range reaches the distance about 1,1 $\mathrm{mm}$ deep into the casting. The results of the hardness measurements are presented in Fig. 3.

On the basis of the performed studies, the following procedure of the semi-FSP process, which can be realized on a typical machining center, was determined. The operation of removing porosities in the surface layer of castings starts with mounting of a component to be processed on a table, e.g. Computerized Numerical Control. Next, the surface layer is subjected to severe plastic deformation by an appropriate rotational tool pressed to the surface and moving along the processed track. As a result, the surface layer of the material is entirely sealed by the stir zone. The process parameters which were selected based on the research include: the penetration depth of about 0.3 $\mathrm{mm}$, rotational speed within the range of 2000-2500 rpm, and head line feed of $150-300 \mathrm{~mm} / \mathrm{min}$. The distance of subsequent penetration zones of the tool was assumed to be between 4 and $6 \mathrm{~mm}$. The implementation of the process, taking into consideration the parameters provided above, ensures the formation of a continuous stir zone in the surface layer. The zone is free from casting defects (porosities, shrinkages), which ensures the tightness of flange joints. 


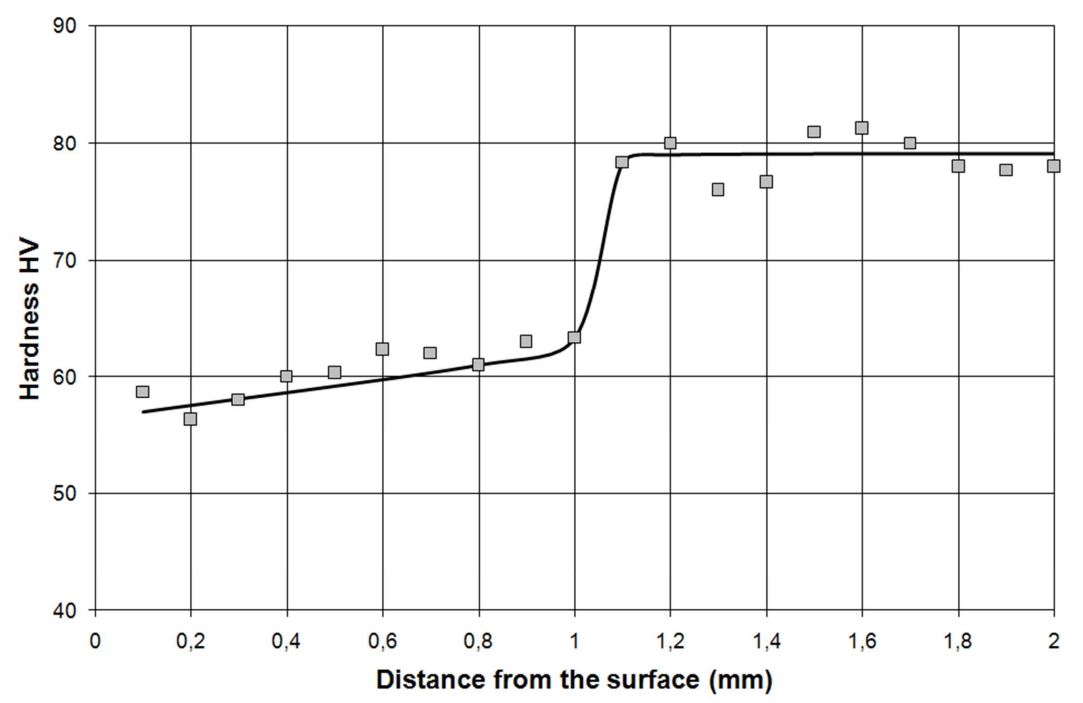

Fig. 3. Change of hardness as the function of the distance from the surface

\section{Summary}

1. The newly developed method of the semi-FSP process enables the removal of casting defects (porosities, discontinuities) from the surface layer of a product. The characteristics of the proposed process is the redesign of a tool shape, which is not equipped with a feature penetrating and stirring the material (pin). Moreover, the process does not require the usage of sophisticated devices or tilting the tool relative to the treated surface during the process.

2. The deformation of the surface layer of the material is performed by friction stir with the use of pressing and rotating tool. The depth of tool insertion was $0.3 \mathrm{~mm}$, however the processed thickness was up to $1.1 \mathrm{~mm}$.

3. The deformed surface layer of the material is free from casting defects which were permanently removed. In this context, the process is useful for repairing defective castings, and, in the case of the GIS switchgears, it allows the required tightness of the joints to be achieved.

\section{Acknowledgements}

The research work has been supported by the European Union No: POIG.01.01.02-00-015/09-00

\section{References}

[1] R. S. Mishra, M. W. Mahoney: Friction Stir Welding and Processing, (ASM, Ohio, 2007)

[2] Information on http://www.frictec.co.uk

[3] Z.Y. Ma: Metall. Mater. Trans. A Vol. 39A (2008), p. 642-658

[4] S. Lathabai, R. Migeon, V.K. Tyagi, R.G. O’Donnell, Y. Estrin: Mater. Sci. Forum Vol. 618619 (2009), p. 63-67

[5] Z.Y. Ma, S.A. Sharma, R.S. Mishra, M.W. Mahoney: Mater. Sci. Forum Vol. 426-432 (2003), p. 2891-2896

[6] S.P. Vaze, J. Xu, R. J. Ritter, K. J. Colligan, J. J. Fisher Jr., J. R. Pickens: Mater. Sci. Forum Vol. 426-432 (2003), p.2979-2986

[7] P. Uliasz, T. Knych, A. Mamala: Arch.of Metal.and Mate Vol. 54 (2009), p. 711-721 